\title{
The influence of the number of screws and additional surgical procedures on outcome in hallux valgus treatment
}

\author{
Thorsten Jentzsch ${ }^{1 *} \mathbb{D}$, Niklas Renner ${ }^{1}$, Richard Niehaus ${ }^{1}$, Jan Farei-Campagna ${ }^{1}$, Marcel Deggeller ${ }^{2}$,
} Fabrice Scheurer ${ }^{2}$, Katie Palmer ${ }^{3}$ and Stephan H. Wirth'

\begin{abstract}
Background: Surgical treatment of hallux valgus (HV) is one of the major flagships of orthopedic surgeons. Due to relatively unsatisfactory radiological and clinical outcomes, the search for the best surgical technique and causes for unsatisfactory outcomes continues. The objective was to investigate associations of the number of screws and additional surgical techniques for HV with radiological and clinical outcome after reversed L-shaped osteotomy (ReveL).

Methods: A retrospective cohort study of adults from a single University Hospital between 2004 and 2013 was performed. The primary exposure was the number of screws (one vs two) used for osseous fixation after ReveL. The secondary exposure was an additional surgical technique for HV (e.g., Akin osteotomy). The primary outcome was a radiological recurrence of $\mathrm{HV}\left(\mathrm{HV}\right.$ angle $\left.(\mathrm{HVA})>15^{\circ}\right)$ at last follow-up. The secondary outcomes were limited patient satisfaction, complication, revision surgery, and elective hardware removal. Odds ratio (OR) and 95\% confidence interval (Cl) were estimated by logistic regression adjusting for confounders.

Results: The recurrence was $45 \%$ less likely with the use of one screw, independent of age, sex, additional technique, and preoperative HVA (odds ratio $\left.\left(\mathrm{OR}_{\text {adjusted }}\right)=0.55[95 \% \mathrm{Cl} 0.30-0.98], p=0.043\right)$. The recurrence was $162 \%$ more likely with an additional surgical technique for HV (ORadjusted $=2.62$ [1.24-5.52], $p=0.011)$.

Conclusion: In ReveL for HV, a single screw (instead of two screws) may be sufficient enough for a similar or even better outcome, which may also reduce costs. Additional surgical procedures for $\mathrm{HV}$ may be refrained from if possible. Due to limitations of a retrospective study, results may need validation with clinical trials.
\end{abstract}

Keywords: Hallux valgus (HV), Reversed L-shaped osteotomy (ReveL), Long plantar arm osteotomy, Screws, Recurrence, Patient satisfaction

\section{Background}

Hallux valgus deformity (HV) is a very common disease, affecting about every fourth individual up to 65 years and around every third individual later on in life [1]. Patient satisfaction after HV surgery (77.4\%) is lower than that in other typical orthopaedic procedures, such as total hip arthroplasty (91.9\%) [2]. Thus, the search for the optimal surgical technique and causes for unsatisfactory outcomes remains of current interest.

\footnotetext{
* Correspondence: thorsten.jentzsch@gmail.com;

thorsten.jentzsch@balgrist.ch

${ }^{1}$ Department of Orthopaedics, Balgrist University Hospital, University of

Zurich, Forchstrasse 340, 8008 Zurich, Switzerland

Full list of author information is available at the end of the article
}

There are many different surgical techniques for HV [3]. Instead of using a V-shaped osteotomy [4], the distal metatarsal (biplanar) reversed L-shaped osteotomy (ReveL) utilizes a short dorsal vertical and long plantar horizontal osteotomy providing high corrective power and intrinsic mechanical stability [5-7]. A tarsometatarsal arthrodesis with two crossed screws may be added in cases, where hypermobility of the first tarsometatarsal joint is observed during clinical examination [8-10]. A phalangeal Akin osteotomy with one screw can also be used as an additional procedure to obtain more angular and rotational correction $[11,12]$.

Although unknown for the distal metatarsal bone, in the proximal metatarsal bone, long plantar arm 
osteotomies may have less stability than short plantar arm osteotomies [13]. Therefore, in theory, strong fixation of a distal metatarsal osteotomy may be needed in order to avoid osteotomy failure and recurrence of HV. Although the use of one screw has been mainly reported in the literature, in theory, two screws offer a stronger fixation than one screw. In line with this assumption, two screws have been associated with faster time to healing of osteotomies after chevron osteotomy $(n=52)$ [14]. However, a recent study has not found any differences in time to healing of osteotomies after chevron osteotomy using one or two screws $(n=75)$ [15]. Two screws are not only more expensive but also bulkier, which may lead to tissue irritation and hardware removal. Furthermore, additional surgical techniques for HV may help correcting greater deformities [16]. However, it remains unknown if the number of screws and additional surgical techniques for HV are associated with radiological and clinical outcome after long plantar arm osteotomies.

Previous studies about long plantar arm osteotomies did not investigate the chosen exposures, i.e., the number of screws and additional surgical techniques for $\mathrm{HV}$ on unsatisfactory radiological and clinical outcomes. The objective of the current study is to investigate associations of the number of screws and additional surgical techniques for $\mathrm{HV}$ with radiological and clinical outcome after ReveL for HV.

\section{Methods}

\section{Study design}

A retrospective cohort study with a superiority design and an internal comparison group was performed. It was part of a Master's thesis, and the results about different study aims are described elsewhere [17-19]. Patient charts with radiological and clinical data from the Balgrist University Hospital in Switzerland between January 2004 and December 2013 were examined. Ethics approval was given by the local ethics committee (cantonal ethics committee Zurich 2015-0480), allowing this retrospective study with a large number of patients to be performed without the need for individually signed informed consent.

\section{Surgical technique}

The surgical technique is described in more detail elsewhere [18]. Briefly, surgery was only performed for painful HV. ReveL was carried out with a short dorsal vertical and long plantar horizontal osteotomy (beginning dorsally 1 centimeter $(\mathrm{cm})$ proximal to the metatarsophalangeal (MTP) joint, then changing direction to a proximally directed osteotomy in the middle of the dorsoplantar distance before exiting the plantar cortex about $4 \mathrm{~cm}$ proximal to the MTP joint; keeping the biplanar option of medial wedge resection when needing decrease of the distal metatarsal angle). Fixation was achieved with one or two $2.4 \mathrm{~mm}$ cortex screws directed dorsoplantarly, and postoperative care consisted of unrestricted ambulation in a postoperative shoe with a rigid sole for 4-6 weeks [20].

\section{Exposure and outcome measures}

The inclusion criteria were primary ReveL for $\mathrm{HV}$ in adult patients. The local database (KISIM; CISTEC AG, Zurich, Switzerland) was searched for the key term "hallux valgus" (Fig. 1). Several exclusion criteria were applied. Eventually, 827 cases were investigated in this study. Patient charts were investigated utilizing the local database (KISIM) and imaging software (IMPAX 6.4.0. 6010 and IMPAX Orthopaedic Tools, Agfa-Gevaert N.V. (Agfa), Mortsel, Belgium). The data were gathered anonymously with REDCap (version 6.11.5; Vanderbilt University, Nashville, TN, USA) and cleaned with Microsoft Excel (version 2010; Microsoft Corporation, Redmond, WA, USA) as well as Stata/IC (version 13.1; StataCorp LP, College Station, TX, USA).

The main exposure variable was the number of screws (one or two) used for fixation of the osteotomy during ReveL (Figs. 2 and 3). The secondary exposure variable was the use of additional surgical techniques for $\mathrm{HV}$ (no or yes), which consisted of tarsometatarsal arthrodesis (no or yes) and/or Akin osteotomy (no or yes). A tarsometatarsal arthrodesis was added if clinical examination revealed hypermobility of the first ray in the tarsometatarsal joint. An Akin osteotomy was performed if $\mathrm{HV}$ interphalangeus (lateral deviation of the distal phalanx in the interphalangeal joint) was found. As explained in Tables 2 and 3, other documented exposure variables, potential confounders, and/or effect modifiers were considered. The time periods were chosen according to the local changes in staff that occurred in the foot and ankle team in 2007 and consecutive changes in personal preferences for the use of one or two screws. The performance of an additional surgical procedure on the foot consisted of any other simultaneous surgery on the foot, such as the Hohmann technique (proximal phalangeal head resection of the lesser toes) for hammer foot deformity or Coughlin osteotomy (longitudinal diaphyseal osteotomy of the fifth metatarsal bone) for Bunionette deformity [21, 22].

The primary (categorical) outcome variable was the radiological recurrence of $\mathrm{HV}\left(\mathrm{HV}\right.$ angle $\left.(\mathrm{HVA})>15^{\circ}\right)$ at last radiological follow-up [23]. The secondary (categorical) clinical outcome variables were limited patient satisfaction, complication, revision surgery, and elective hardware removal.

\section{Statistical methods}

The data were non-normally distributed according to the skewness and kurtosis test for normality, and 


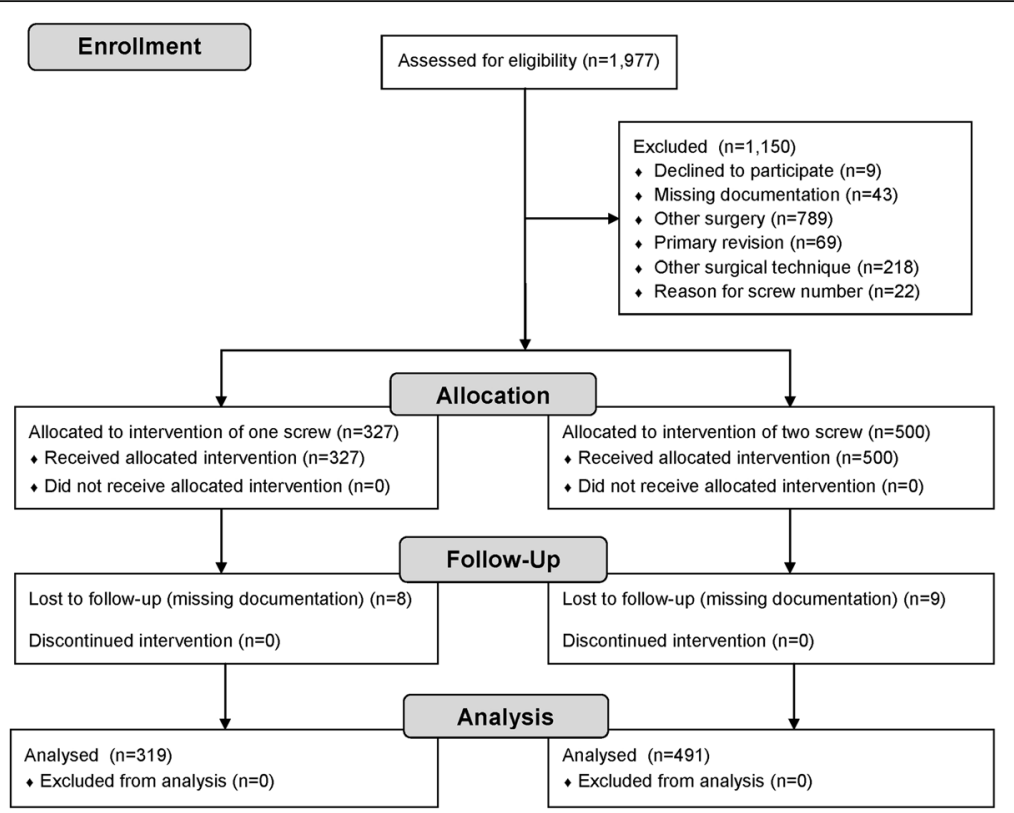

Fig. 1 Flow chart of case enrolment in this retrospective cohort study between January 2004 and December 2013 [34]

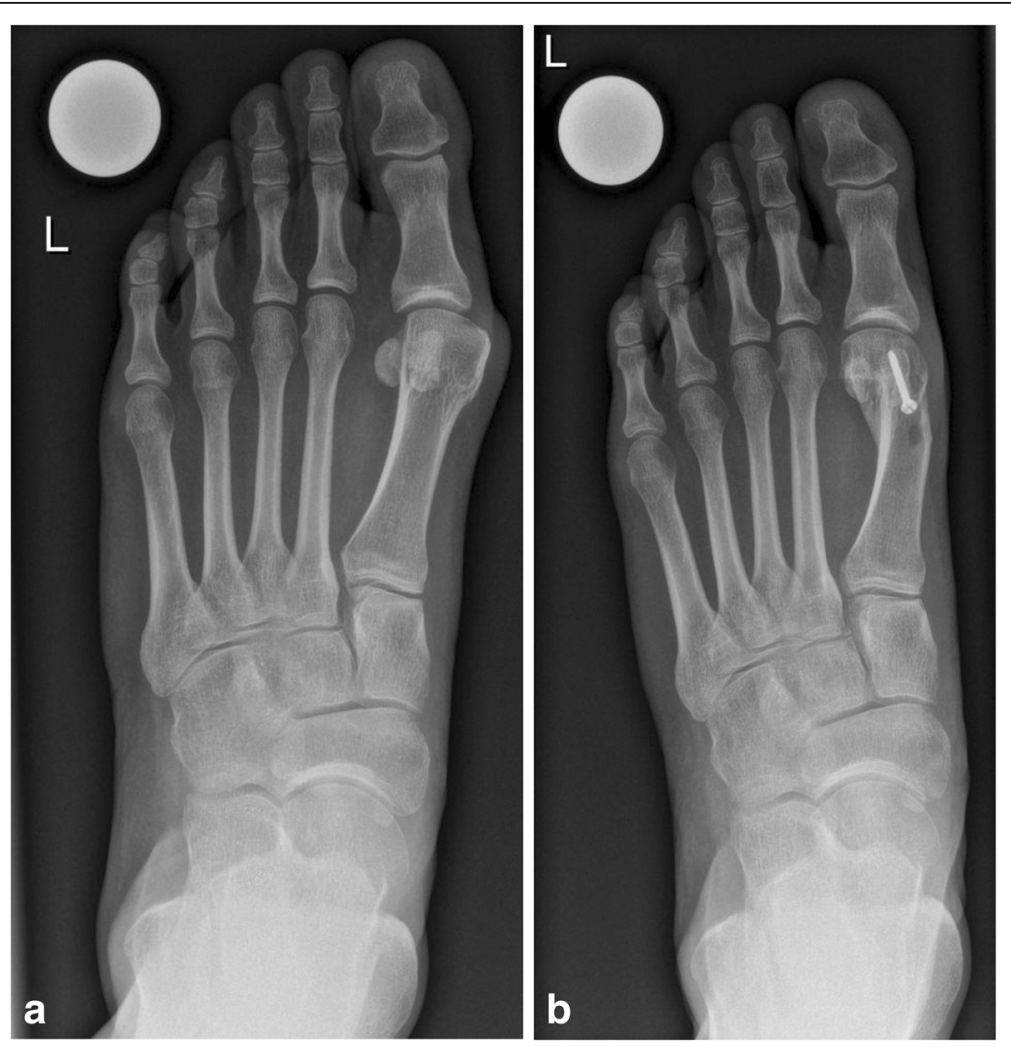

Fig. 2 Conventional dorsoplantar radiographs of the left foot in a 37-year-old female. a Preoperative radiograph showing a hallux valgus deformity. b Postoperative radiograph showing correction of a hallux valgus deformity 1 year after reversed L-shaped osteotomy (ReveL) using one screw 


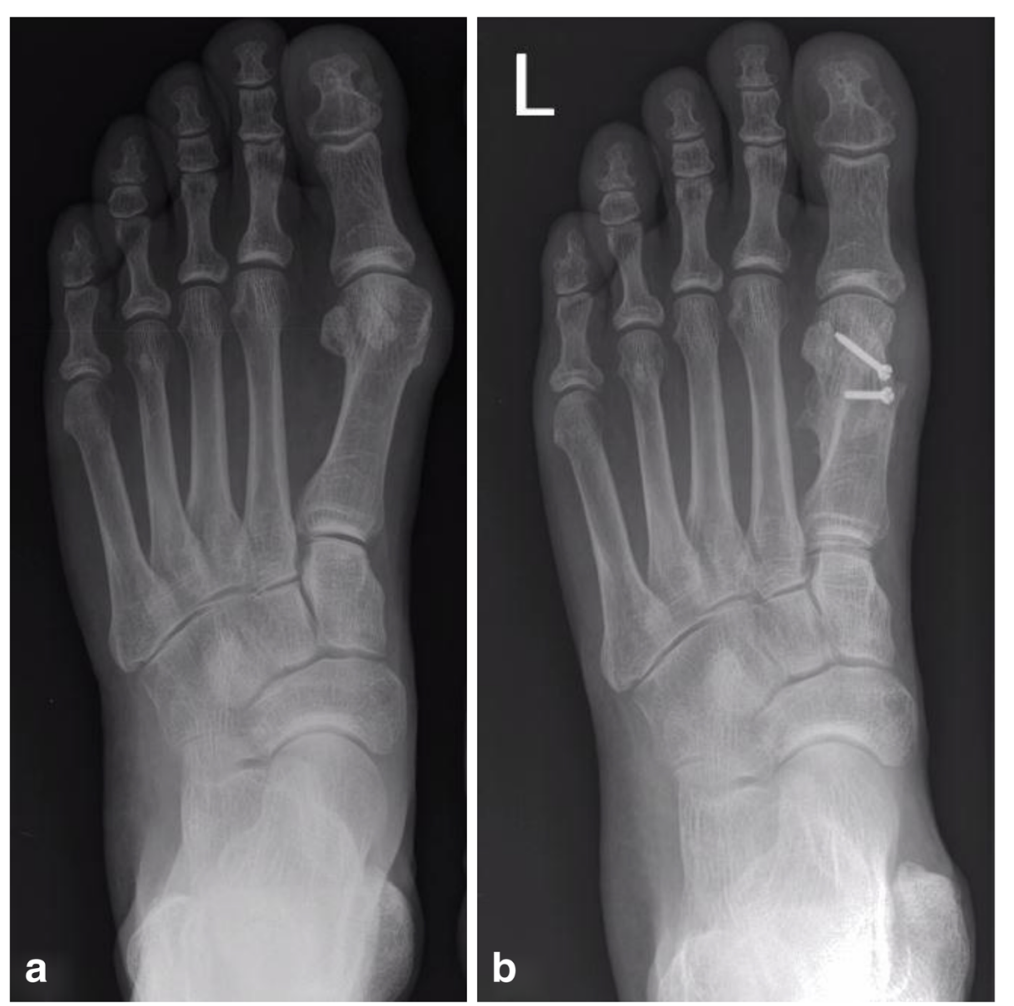

Fig. 3 Conventional dorsoplantar radiographs of the left foot in a 60-year-old male. a Preoperative radiograph showing a hallux valgus deformity. b Postoperative radiograph showing correction of hallux valgus deformity 1 year after reversed L-shaped osteotomy (ReveL) using two screws

medians (interquartile range (IQR)) are provided. Categorical data were cross-tabulated and assessed with the chi-squared or Fisher's exact test. Odds ratios (OR) and 95\% confidence intervals (CI) were calculated for each category. Confounders were considered to be factors associated with the radiological recurrence of $\mathrm{HV}$ and the number of screws after ReveL without being on the causal pathway between both variables. A priori, age and sex were defined as confounders since they commonly influence the prevalence of diseases, including HV [24-27]. Preoperative HVA was also chosen as an a priori confounder since it represents the severity of HV and influences the recurrence of HV after surgery [28]. Further confounding was assumed when the crude and adjusted estimates differed by $\geq 10 \%$. Effect modification was present when stratum-specific estimates differed according to the test for heterogeneity. Adjusted Mantel-Haenszel estimates for potential confounders and stratum-specific estimates for effect modifiers were calculated for the association between radiological recurrence of $\mathrm{HV}$ and the number of screws after ReveL. Likewise, secondary outcomes as well as the remaining exposure variables were assessed accordingly. To study the objectives of associations between the number of screws after ReveL and additional surgical techniques for HV with radiological recurrence of $\mathrm{HV}$, logistic regression was used to obtain a causal model. Likelihood ratio tests were used to compare different models with and without interaction terms and linear trends. A Wald test assessed differences in the odds in different categories of a single variable.

Among others, bias was limited by calculation of a sample size (type II error), exclusion of cases with a reason for a specific number of screws (selection bias), hypothesis testing without knowledge of surgeons and patients (blinding, performance, and reporting bias), adjusting for confounders including time period as a surrogate for changes in staff and preferences for the number of screws (performance bias), and disclosure of missing values (selection bias). A clinically relevant difference in radiological recurrence of $10 \%$ would be important to detect. At a significance level of $5 \%$ and power of $80 \%$, this required $\geq 199$ cases per group. Statistical significance was assumed at a 5\% level. Analyses were carried out with Stata/IC (StataCorp LP).

\section{Results}

\section{Participants}

At a median follow-up of 12.0 (IQR 4.0-19.0) months, 17 (2.1\%) cases were lost to follow-up and 810 (97.9\%) cases analysed. There were no differences between those 
that were lost to follow-up and those included in the study regarding the number of screws $(p=0.522)$.

While two screws were more commonly used in the earlier time period (one screw, $n=53$ [11.5\%] vs two screws, $n=409$ [88.5\%], $p<0.001$ ), one screw was more commonly used in the second period (one screw, $n=266$ [76.4\%] vs two screws, $n=82$ [23.6\%], $p<0.001)$.

\section{Exposure variables}

More cases were treated with two screws after ReveL $(n=491[60.6 \%])$ compared to one screw $(n=319$ [39.4\%]) (Table 1). The stand-alone use of ReveL for HV $(n=514[63.5 \%])$ was more common than additional surgical techniques for $\operatorname{HV}(n=296$ [36.5\%]). An additional Akin osteotomy $(n=289$ [35.7\%]) was more common than tarsometatarsal arthrodesis (21 [2.6\%]). The majority of cases did not receive additional surgery on the remaining foot $(n=496[61.2 \%])$.

\section{Multivariate analysis of primary outcome}

The logistic regression model demonstrated moderate evidence that radiological recurrence of $\mathrm{HV}$ was $45 \%$ less likely with the use of one screw for fixation after ReveL; irrespective of age, sex, preoperative HVA, additional surgical technique for $\mathrm{HV}$, time period, and BMI

Table 1 Exposure variables of cases treated with reversed L-shaped osteotomy (ReveL) for hallux valgus deformity $(n=810)$

\begin{tabular}{|c|c|c|c|}
\hline Variable & Category & $N_{\text {total }}(\%)$ & $N_{\text {category }}(\%)$ \\
\hline \multicolumn{2}{|c|}{ One screw after ReveL } & $810(100.0)$ & \\
\hline & No & & $491(60.6)$ \\
\hline & Yes & & $319(39.4)$ \\
\hline \multicolumn{2}{|c|}{ Additional surgical technique for $\mathrm{HV}^{*}$} & $810(100.0)$ & \\
\hline & No & & $514(63.5)$ \\
\hline & Yes & & $296(36.5)$ \\
\hline \multicolumn{2}{|c|}{ Additional tarsometatarsal arthrodesis } & $810(100.0)$ & \\
\hline & No & & $789(97.4)$ \\
\hline & Yes & & $21(2.6)$ \\
\hline \multicolumn{2}{|c|}{ Additional Akin osteotomy } & $810(100.0)$ & \\
\hline & No & & $521(64.3)$ \\
\hline & Yes & & $289(35.7)$ \\
\hline \multicolumn{2}{|c|}{ Time period } & $810(100.0)$ & \\
\hline & $2004-2007$ & & $462(57.0)$ \\
\hline & 2008-2013 & & $348(43.0)$ \\
\hline \multicolumn{2}{|c|}{ Additional surgery on foot ${ }^{\dagger}$} & $810(100.0)$ & \\
\hline & No & & $496(61.2)$ \\
\hline & Yes & & $314(38.8)$ \\
\hline
\end{tabular}

Abbreviations: $N$ number, \% percent, IQR interquartile range, ReveL reversed L-shaped osteotomy, HV hallux valgus deformity

*Tarsometatarsal arthrodesis or Akin osteotomy

${ }^{\dagger}$ Any other surgery on the foot except for HV (e.g., Hohmann technique of lesser toes or Coughlin osteotomy of fifth metatarsal)
$\left(\mathrm{OR}_{\text {adjusted }}=0.55 \quad[95 \% \quad \mathrm{CI} \quad 0.30-0.98], \quad p=0.043\right)$ (Table 2). It also showed moderate evidence that radiological recurrence of $\mathrm{HV}$ was $162 \%$ more likely with the use of additional surgical technique for $\mathrm{HV}$ than without the use of additional surgical technique for $\mathrm{HV}\left(\mathrm{OR}_{\text {adjusted }}=2.62[1.24-5.52], p=0.011\right)$.

\section{Multivariate analysis of secondary outcomes}

There was no evidence of an association of the secondary outcome variables (limited patient satisfaction, complication, revision surgery, and elective hardware removal) with the number of screws used for fixation after ReveL in the multivariate analysis (Table 3).

No evidence of associations of limited patient satisfaction with the number of screws used for fixation after ReveL $\left(\mathrm{OR}_{\text {adjusted }}=0.64\right.$ [95\% CI 0.37-1.08], $\left.p=0.096\right)$, additional surgical technique for $\mathrm{HV}\left(\mathrm{OR}_{\text {adjusted }}=0.74\right.$ [95\% CI 0.471.18 ], $p=0.202)$, and time period $\left(\mathrm{OR}_{\mathrm{adjusted}}=1.69[95 \% \mathrm{CI}\right.$ $0.97-2.94], p=0.062$ ) were noted.

There was no evidence for associations of complications with the number of screws after ReveL $\left(\mathrm{OR}_{\text {adjusted }}=0.50\right.$ [95\% CI 0.20-1.24], $p=0.133$ ), additional surgical technique for $\mathrm{HV}\left(\mathrm{OR}_{\text {adjusted }}=0.54\right.$ [95\% CI $0.71-3.31$ ], $p=0.272)$, and time period $\left(\mathrm{OR}_{\text {adjusted }}=1.51[95 \% \mathrm{CI}\right.$ 0.59-3.88], $p=0.391$ ).

No evidence for associations of revision surgery with the number of screws after ReveL (OR adjusted $=0.39$ [95\% CI $0.69-2.16], p=0.279$ ), additional surgical technique for $\mathrm{HV}\left(\mathrm{OR}_{\text {adjusted }}=1.23\right.$ [95\% CI 0.42-3.62], $\left.p=0.710\right)$, and time period $\left(\mathrm{OR}_{\text {adjusted }}=1.18\right.$ [95\% CI $0.26-5.47$ ], $p=0.830$ ) were observed.

There was no evidence of associations of elective hardware removal with the number of screws $\left(\mathrm{OR}_{\text {adjusted }}=0.86\right.$ [95\% CI 0.56-1.33], $p=0.503$ ), additional surgical techniques for $\mathrm{HV}\left(\mathrm{OR}_{\text {adjusted }}=1.14\right.$ [95\% CI 0.78-1.66], $p=0.492)$, and time period $\left(\mathrm{OR}_{\text {adjusted }}=1.20[95 \% \mathrm{CI}\right.$ $0.76-1.89], p=0.492)$. The cumulative probability of complication and revision surgery did not differ between cases with one screw and those with two screws after ReveL ( $p=0.902$ and $p=0.453$, respectively) (Fig. 4a, b). The cumulative probability of no elective hardware removal was lower in cases with one screw after ReveL than in those with two screws after ReveL $(p=0.001)$ (Fig. 4c). The median time to hardware removal was shorter in cases with one screw after ReveL (12.0 [IQR 8.0-19.0] months) than those with two screws after ReveL (14.5 [9.0-32.0] months).

\section{Discussion}

In this Swiss single-center cohort study, after adjustment for confounders, there were independent associations of the use of one screw for fixation after ReveL for HV and less radiological recurrence of $\mathrm{HV}$ as well as the use of additional surgical techniques for $\mathrm{HV}$ and increased 
Table 2 Logistic regression model for several factors associated with radiological recurrence of hallux valgus deformity (HV) (hallux valgus angle $(\mathrm{HVA})>15^{\circ}$ ) and the number of screws used for fixation after reversed L-shaped osteotomy (ReveL) for HV $(n=799)$

\begin{tabular}{llll}
\hline Main effect of variable & Stratum-specific effect of variable & Category & Adjusted OR (95\% Cl) $^{*}$
\end{tabular}

One screw after ReveL for HV

$\begin{array}{ll}\text { No } & 1.00 \text { (reference) } \\ \text { Yes } & 0.55(0.30-0.98)\end{array}$

Additional surgical technique for HV

$\begin{array}{ll}\text { No } & 1.00 \text { (reference) } \\ \text { Yes } & 2.62(1.24-5.52)\end{array}$

Time period

$\begin{array}{ll}2004-2007 & 1.00 \text { (reference) } \\ 2008-2013 & 1.50(0.91-2.47)\end{array}$

Abbreviations: $O R$ odds ratio, \% percent, $\mathrm{Cl}$ confidence interval, ReveL reversed L-shaped osteotomy, $H V$ hallux valgus deformity

*Adjusted for confounders and effect modifiers: age, sex, preoperative hallux valgus angle, number of screws, additional surgical technique for hallux valgus, time period, and body mass index. Note: The effect modifier Akin osteotomy was not included in the final model since it is already included in additional surgical techniques for hallux valgus

${ }^{\dagger}$ Wald test

radiological recurrence of $\mathrm{HV}$. There were no associations of the number of used screws with limited patient satisfaction, complication, revision surgery, and elective hardware removal.

The literature about ReveL is very limited, and the level of evidence of the relevant studies is low [20, 29-33]. A previous small study showed that time to healing was faster with two screws compared to one screw after chevron osteotomy, but another small study did not find any differences $[14,15]$. Our results add to this literature in that we found an independent association between the number of screws and radiological recurrence of $\mathrm{HV}$, but not with the clinical

Table 3 Characteristics of cases treated with reversed L-shaped osteotomy (ReveL) for hallux valgus deformity using one or two screws and their association with secondary outcome variables $(n=799)$

\begin{tabular}{|c|c|c|c|c|}
\hline \multirow[b]{2}{*}{ Variable } & \multirow[b]{2}{*}{ Category } & \multicolumn{2}{|l|}{ One screw } & \multirow[b]{2}{*}{$p$ value $^{*}$} \\
\hline & & No & Yes & \\
\hline \multicolumn{5}{|c|}{ Limited patient satisfaction $^{\dagger}$} \\
\hline & No, $N(\%)$ & $402(83.4)$ & $273(86.2)$ & \\
\hline & Yes, N (\%) & 80 (16.6) & $44(13.8)$ & \\
\hline & OR adjusted $\left(95 \% \mathrm{Cl}^{\ddagger}\right.$ & 1.00 (reference) & $0.64(0.37-1.08)$ & 0.096 \\
\hline \multicolumn{5}{|c|}{ Complication $^{\S}$} \\
\hline & No, N (\%) & $457(94.8)$ & $305(96.2)$ & \\
\hline & Yes, N (\%) & $25(5.2)$ & $12(3.8)$ & \\
\hline & $\mathrm{OR}_{\text {adjusted }}(95 \% \mathrm{Cl})^{\ddagger}$ & 1.00 (reference) & $0.50(0.20-1.24)$ & 0.133 \\
\hline \multicolumn{5}{|c|}{ Revision surgery } \\
\hline & No, N (\%) & 467 (96.9) & $312(98.4)$ & \\
\hline & Yes, N (\%) & $15(3.1)$ & $5(1.6)$ & \\
\hline & $\mathrm{OR}_{\text {adjusted }}(95 \% \mathrm{Cl})^{\|}$ & 1.00 (reference) & $0.39(0.07-2.16)$ & 0.279 \\
\hline \multicolumn{5}{|c|}{ Elective hardware removal } \\
\hline & No, N (\%) & $355(73.7)$ & $229(72.2)$ & \\
\hline & Yes, N (\%) & $127(26.3)$ & $88(27.8)$ & \\
\hline & $\mathrm{OR}_{\text {adjusted }}(95 \% \mathrm{Cl})^{\ddagger}$ & 1.00 (reference) & $0.86(0.56-1.33)$ & 0.503 \\
\hline \multicolumn{5}{|c|}{$\begin{array}{l}\text { *Wald test } \\
\text { 'Limited patient satisfaction was defined as dissatisfied or improved, while patient satisfaction was defined as satisfied or very satisfied } \\
{ }^{+} \text {Adjusted for potential confounders and effect modifiers: age, sex, body mass index, additional surgical technique for hallux valgus, preoperative hallux valgus } \\
\text { angle, and time period } \\
\text { sDefined as infection, osseous necrosis, non-union, complex regional pain syndrome, and revision }\end{array}$} \\
\hline
\end{tabular}




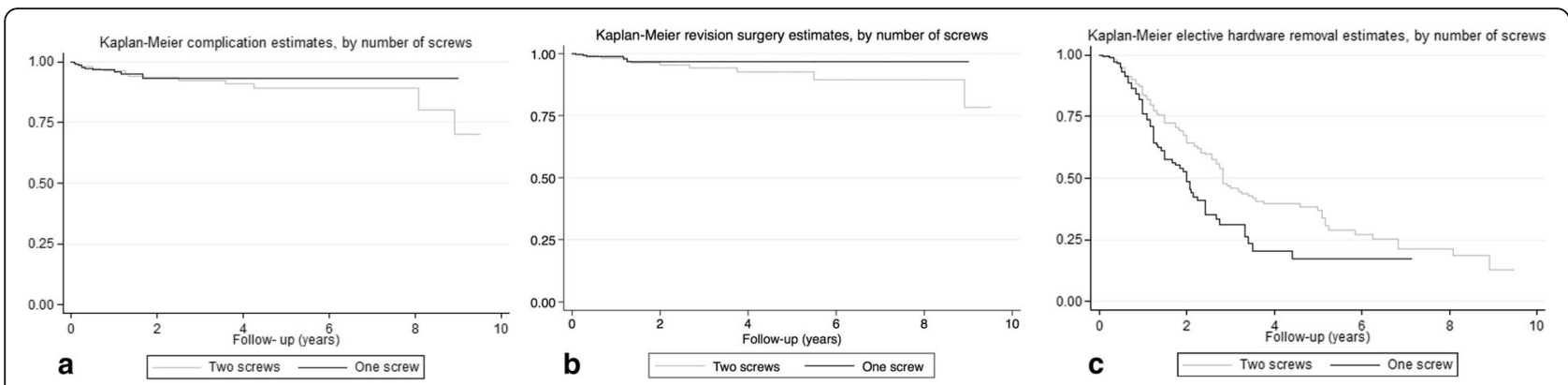

Fig. 4 Kaplan-Meier curves. a Kaplan-Meier curve for complication after reversed L-shaped osteotomy (ReveL) for hallux valgus deformity (HV) $(p=0.902)(n=810)$. b Kaplan-Meier curve for revision surgery after reversed L-shaped osteotomy (ReveL) for HV $(p=0.453)(n=810)$. c Kaplan-Meier curve for elective hardware removal after reversed L-shaped osteotomy (ReveL) for HV $(p=0.001)(n=810)$

outcome after ReveL. Although additional surgical techniques were described to have higher correction of $\mathrm{HV}$, our results question their use if not absolutely necessary for substantially better correction of HV since they were associated with higher radiological recurrence of HV [16].

The evidence of an association between the number of screws with radiological recurrence of HV may be present since deforming forces that act on the first ray may be lower than those needed for failure of fixation. In other words, one screw may be strong enough to hold the osteotomy site in place. Similarly, no evidence of an association between the number of screws with clinical outcome may have been found since one screw may not be associated with less soft tissue irritation, swelling, and foreign body sensation. Although validation of the following is needed in further studies, one screw may potentially be considered for ReveL for HV due to its lower cost (23.60 Swiss Francs for one screw (2.4 mm cortex screw; Synthes, PA, USA)).

It is plausible that additional surgical techniques for $\mathrm{HV}$ are associated with increased radiological recurrence of HV because risk of failure inevitably increases with the number of osteotomies and fixations due to a more fragile overall construct. This fact could be used by surgeons when intraoperative ambiguity arises whether or not an additional surgical technique for HV should be used. This is clinically relevant because surgeons often contemplate whether correction of $\mathrm{HV}$ is sufficient or if an additional technique for HV could improve correction.

The fact that one screw was removed faster than two screws could potentially point toward faster bone healing entailing faster elective hardware removal since increasing tissue irritation by one screw is unlikely.

Previous studies about long plantar arm osteotomies consisted of much smaller sample sizes without adjustment for confounders. We provide new findings about potential associations between the number of screws and additional surgical techniques on the radiological and clinical outcomes. This information can be used by patients and orthopedic surgeons during pre-, intra-, and postoperative planning. Hospitals and insurance companies may also be interested in knowing that costs and surgical time could potentially be reduced.

Future studies could perform a superiority randomised controlled trial in order to compare the radiological recurrence and clinical outcome of HV after ReveL using one vs two screws. If possible, only one surgeon should use the same surgical techniques without additional surgical techniques and the same number of screws, preferably one screw, in all patients. A factorial design could be added to confirm our borderline evidence that additional surgical techniques for $\mathrm{HV}$ are associated with increased radiological recurrence of $\mathrm{HV}$.

There are several limitations to this study. First, random assignment of cases limiting selection bias can be assumed by only including cases, where the surgical report did not mention a specific reason for the chosen number of screws. However, the risk of recall bias of surgeons (i.e., failure to mention a specific reason for number of screws) remains, although it is likely to be small since surgical reports are immediately written after the surgery. If surgeons forgot to mention that there was a specific risk for two screws, differential misclassification may have led to underestimation of the strength of an association between radiological recurrence of $\mathrm{HV}$ and the number of screws.

Second, blinding of surgeons to the study hypothesis limiting performance bias, differential treatment response, and misclassification may be assumed since surgeons did not know that this study would be conducted later on. Patients were usually told preoperatively that osteotomies would be fixed with implant material, such as one or two screws. However, a certain risk for information bias remains due to the retrospective nature of this study.

Third, due to the long study period and nature of a teaching hospital, numerous different surgeons performed surgeries, and usually, $\geq 2$ surgeons were present 
at each surgery, rendering stratification difficult due to too many strata with small numbers. This is a potential confounder that cannot directly be controlled. However, every surgical procedure is supervised by a responsible senior surgeon, who follows the principles of the team leader, which ensures high and similar quality of each surgery. Choosing the number of screws is also usually in accordance with the personal preference of the senior surgeon. Selection bias and attenuation of effects may have arisen if more difficult cases were surgically treated by more experienced surgeons with a personal preference for one screw or vice versa. To adjust for this potential issue, two time periods were chosen and controlled for. Since the time period was chosen according to the time where different staff of the foot and ankle team was working, different philosophies of fixation techniques were indirectly adjusted for. Lastly, cases differed in their follow-up time due to the retrospective nature of this study. Although surveillance bias may have been present, the follow-up of patients is usually very good, and therefore, the last follow-up can be assumed to equal the final result.

\section{Conclusions}

In ReveL for HV, a single screw (instead of two screws) may be sufficient enough for a similar of even better outcome, which may also reduce costs. Additional surgical procedures for HV may be refrained from if possible. Due to limitations of a retrospective study, the results may need validation with clinical trials.

\section{Abbreviations}

$\Delta$ : Difference; $\mathrm{Cl}$ : Confidence interval; HV: Hallux valgus deformity; HVA: Hallux valgus angle; IQR: Interquartile range; OR: Odds ratio: ReveL: Reversed L-shaped osteotomy; vs: Versus

\section{Acknowledgements}

This manuscript follows around a third of content of an unpublished Master's thesis written by the first author in the realm of a project report at the London School of Hygiene \& Tropical Medicine. The other two thirds of content about other study aims are provided elsewhere.

\section{Availability of data and materials}

All the data analyzed during this study are included in this article.

\section{Authors' contributions}

TJ contributed to the idea, conception and design, acquisition of the data, analysis and interpretation of the data, and drafting of the manuscript. NR participated in supporting the idea and acquisition of the data. RN, JFC, MD, and FS helped in acquisition of the data. KP was involved in conception and design and analysis strategy of the data. SW supervised the project. All authors contributed equally to the revision of the manuscript and final approval of the version to be published.

\section{Ethics approval and consent to participate}

Ethics approval was given by the local ethics committee (cantonal ethics committee Zurich 2015-0480), allowing this retrospective study with a large number of patients to be performed without the need for individually signed informed consent to participate.

\section{Consent for publication}

This retrospective study with a large number of patients was allowed by the local ethics committee (cantonal ethics committee Zurich 2015-0480) to be performed without the need for individually signed informed consent for publication.

\section{Competing interests}

The authors declare that they have no competing interests.

\section{Publisher's Note}

Springer Nature remains neutral with regard to jurisdictional claims in published maps and institutional affiliations.

\section{Author details}

${ }^{1}$ Department of Orthopaedics, Balgrist University Hospital, University of Zurich, Forchstrasse 340, 8008 Zurich, Switzerland. ${ }^{2}$ University of Zurich Zurich, Switzerland. ${ }^{3}$ San Camillo Hospital IRCCS, Venice, Italy.

Received: 19 January 2018 Accepted: 29 March 2018

Published online: 25 April 2018

\section{References}

1. Nix S, Smith M, Vicenzino B. Prevalence of hallux valgus in the general population: a systematic review and meta-analysis. J Foot Ankle Res. 2010;3:21

2. Lim JB, Chou AC, Yeo W, Lo NN, Chia SL, Chin PL, et al. Comparison of patient quality of life scores and satisfaction after common orthopedic surgical interventions. Eur J Orthop Surg Traumatol. 2015;25(6):1007-12.

3. Wu DY, Lam KF. Osteodesis for hallux valgus correction: is it effective? Clin Orthop Relat Res. 2015;473(1):328-36.

4. Austin DW, Leventen EO. A new osteotomy for hallux valgus: a horizontally directed " $V$ " displacement osteotomy of the metatarsal head for hallux valgus and primus varus. Clin Orthop Relat Res. 1981;157:25-30.

5. Favre P, Farine M, Snedeker JG, Maquieira GJ, Espinosa N. Biomechanical consequences of first metatarsal osteotomy in treating hallux valgus. Clin Biomech (Bristol, Avon). 2010;25(7):721-7.

6. Austin DW, Leventen EO. V-osteotomy of the first metatarsal head, Scientific exhibit. Chicago: Annual Meeting of the American Academy of Orthopaedic Surgeons; 1968.

7. Vienne P, Favre P, Meyer D, Schoeniger R, Wirth S, Espinosa N. Comparative mechanical testing of different geometric designs of distal first metatarsal osteotomies. Foot Ankle Int. 2007;28(2):232-6.

8. Doty JF, Coughlin MJ. Hallux valgus and hypermobility of the first ray: facts and fiction. Int Orthop. 2013:37(9):1655-60.

9. Baxter JR, Mani SB, Chan JY, Vulcano E, Ellis SJ. Crossed-screws provide greater tarsometatarsal fusion stability compared to compression plates. Foot Ankle Spec. 2015;8(2):95-100.

10. Willegger M, Holinka J, Ristl $R$, Wanivenhaus $A H$, Windhager $R$, Schuh $R$. Correction power and complications of first tarsometatarsal joint arthrodesis for hallux valgus deformity. Int Orthop. 2015;39(3):467-76.

11. Geng X, Wang C, Ma X, Wang X, Huang J, Zhang C, et al. Mobility of the first metatarsal-cuneiform joint in patients with and without hallux valgus: in vivo three-dimensional analysis using computerized tomography scan. J Orthop Surg Res. 2015;10:140.

12. Al-Nammari SS, Christofi T, Clark C. Double first metatarsal and akin osteotomy for severe hallux valgus. Foot Ankle Int. 2015;36(10):1215-22.

13. Gocke SP, Rottier FJ, Havey RM, Renner SM, Patwardhan AG, Carandang G. Quantitative analysis of the long- and short-arm crescentic shelf bunionectomy osteotomies in fresh cadaveric matched pair specimens. J Foot Ankle Surg. 2011;50(2):158-64.

14. Murphy RM, Fallat LM, Kish JP. Axial loading screw fixation for chevron type osteotomies of the distal first metatarsal: a retrospective outcomes analysis. J Foot Ankle Surg. 2014:53(1):52-4.

15. Andrews BJ, Fallat LM, Kish JP. Screw versus plate fixation for chevron osteotomy: a retrospective study. J Foot Ankle Surg. 2016;55(1):81-4.

16. Lechler P, Feldmann C, Köck FX, Schaumburger J, Grifka J, Handel M. Clinical outcome after chevron-akin double osteotomy versus isolated chevron procedure: a prospective matched group analysis. Arch Orthop Trauma Surg. 2012;132(1):9-13.

17. Jentzsch T. Factors associated with radiological recurrence of hallux valgus deformity and limited patient satisfaction after reversed L- shaped 
osteotomy: a retrospective cohort study in Switzerland. London School of Hygiene \& Tropical Medicine (LSHTM), London, United Kingdom. Unpublished Master's Thesis. 2016.

18. Jentzsch T, Renner N, Niehaus R, Farei-Campagna J, Deggeller M, Scheurer F, Palmer K, Wirth S. Radiological and clinical outcome after reversed L-shaped osteotomy: a large retrospective Swiss cohort study. Manuscript submitted for publication. 2017.

19. Wirth SH, Renner N, Niehaus R, Farei-Campagna J, Deggeller M, Scheurer F, Palmer $\mathrm{K}$, Jentzsch $\mathrm{T}$. The influence of sex and obesity on radiological and clinical outcome after reversed L- shaped osteotomy: a retrospective cohort study in Switzerland. Manuscript in preparation. 2018

20. Helmy N, Vienne P, von Campe A, Espinosa N. Treatment of hallux valgus deformity: preliminary results with a modified distal metatarsal osteotomy. Acta Orthop Belg. 2009;75(5):661-70.

21. Hohmann G. Zur Technik der Hammerzehenoperation. Arch Orthop UnfallChir. 1922;20:417-8.

22. Coughlin MJ. Treatment of bunionette deformity with longitudinal diaphyseal osteotomy with distal soft tissue repair. Foot Ankle. 1991;11(4):195-203.

23. Pentikainen I, Ojala R, Ohtonen P, Piippo J, Leppilahti J. Preoperative radiological factors correlated to long-term recurrence of hallux valgus following distal chevron osteotomy. Foot Ankle Int. 2014;35(12):1262-7.

24. Turan I. Correlation between hallux valgus angle and age. J Foot Surg. 1990;29(4):327-9.

25. Perera AM, Mason L, Stephens MM. The pathogenesis of hallux valgus. J Bone Joint Surg Am. 2011;93(17):1650-61.

26. Hsu YH, Liu Y, Hannan MT, Maixner W, Smith SB, Diatchenko L, et al. Genome-wide association meta-analyses to identify common genetic variants associated with hallux valgus in Caucasian and African Americans. J Med Genet. 2015;52(11):762-9.

27. Golightly YM, Hannan MT, Dufour AB, Renner JB, Jordan JM. Factors associated with hallux valgus in a community-based cross-sectional study of adults with and without osteoarthritis. Arthritis Care Res (Hoboken). 2015;67(6):791-8.

28. Bock P, Kluger R, Kristen KH, Mittlböck M, Schuh R, Trnka HJ. The scarf osteotomy with minimally invasive lateral release for treatment of hallux valgus deformity: intermediate and long-term results. J Bone Joint Surg Am. 2015;97(15):1238-45.

29. Donnelly RE, Saltzman CL, Kile TA, Johnson KA. Modified chevron osteotomy for hallux valgus. Foot Ankle Int. 1994;15(12):642-5.

30. Nery C, Barroco R, Réssio C. Biplanar chevron osteotomy. Foot Ankle Int. 2002;23(9):792-8.

31. Corte-Real NM, Moreira RM. Modified biplanar chevron osteotomy. Foot Ankle Int. 2009;30(12):1149-53.

32. Hofstaetter SG, Schuh R, Trieb K, Trnka HJ. Modified chevron osteotomy with lateral release and screw fixation for treatment of severe hallux deformity. Z Orthop Unfall. 2012;150(6):594-600

33. Vasso M, Del Regno C, D'Amelio A, Schiavone PA. A modified Austin/ chevron osteotomy for treatment of hallux valgus and hallux rigidus. J Orthop Traumatol. 2016;17(1):89-93.

34. Schulz KF, Altman DG, Moher D, Group C. CONSORT 2010 statement: updated guidelines for reporting parallel group randomised trials. BMJ. 2010;340:c332.

\section{Submit your next manuscript to BioMed Central and we will help you at every step:}

- We accept pre-submission inquiries

- Our selector tool helps you to find the most relevant journal

- We provide round the clock customer support

- Convenient online submission

- Thorough peer review

- Inclusion in PubMed and all major indexing services

- Maximum visibility for your research

Submit your manuscript at www.biomedcentral.com/submit

) Biomed Central 